\title{
Negative priming without ignoring
}

\author{
TIMOTHY J. WOOD and BRUCE MILLIKEN \\ McMaster University, Hamilton, Ontario, Canada
}

\begin{abstract}
Negative priming is conventionally defined by slowed responses to a target item that appeared previously as a distractor. As a result, it is widely assumed that negative priming is caused by an act of ignoring. Three experiments are reported in which novel abstract shapes were studied with either "shallow" or "deep" encoding instructions. This study phase was followed by a same-different discrimination task similar to that employed by DeSchepper and Treisman (1996). Same-different discrimination was slower for old than for new target shapes, and this negative priming effect depended on the difficulty of the discrimination task. The results suggest that negative priming may not be caused by the ignoring of a prime stimulus.
\end{abstract}

The notion that inhibitory mechanisms play a critical role in selective attention has gained wide support over the past decade (Moran \& Desimone, 1985; Posner \& Cohen, 1984; Tipper, 1985). One of the empirical phenomena used to examine these inhibitory mechanisms is known as negative priming. Negative priming is usually measured by asking participants to attend and respond selectively to a target, while ignoring a distractor, in each of two consecutive displays. The first display is commonly labeled the prime and the second display is labeled the probe. Negative priming occurs when response times (RTs) are slower for probe targets that correspond to prime distractors than when both dimensions of prime and probe are unrelated to each other. For example, color naming responses to the word BLUE displayed in red are slower following a response to the word RED displayed in yellow than following a response to the word GREEN displayed in yellow (Lowe, 1979; Neill, 1977).

This result contrasts with facilitatory priming effects often observed for both attended and unattended primes (see, e.g., Marcel, 1980), and has led researchers to conclude that selective attention to sources of relevant information is achieved, at least in part, by actively inhibiting sources of irrelevant information (Neill, 1977; Tipper, 1985). The logic underlying this attribution is as follows. If selection of a prime target item is achieved in part by inhibiting the internal representations of prime distracting items, and if this inhibition persists across the temporal interval between the prime and probe, then a response to a probe target that requires access to these inhibited representations may be slowed. This theoretical view is commonly referred to as the distractor inhibition hypothesis.

Although this hypothesis is a widely accepted explanation of negative priming, several empirical results have proven difficult to accommodate within the distractor inhibition framework. For example, Lowe (1979) demon-

Correspondence should be addressed to B. Milliken, Department of Psychology, McMaster University, 1280 Main St. West, Hamilton, ON, Canada L8S 4K1 (e-mail: millike@mcmaster.ca). strated that negative priming can depend on the selective attention demands of the probe task rather than being entirely determined by the selective attention demands of the prime task. Participants were required to identify the color of an incongruent Stroop stimulus (e.g., the word RED displayed in yellow) in the prime display and to identify the color of either a second Stroop stimulus or a simple color patch in the probe display. On trials in which the probe target color corresponded to the previously ignored color word, negative priming was observed only when the probe item was an incongruent Stroop stimulus. More importantly, positive priming was often observed when the probe stimulus was a simple color patch that corresponded to the previously ignored word (see also Moore, 1994; Tipper \& Cranston, 1985). If negative priming provides a measure of the persisting effect of an inhibitory selection process, it is not clear why this effect should depend on the nature of the probe task.

More recently, a finding reported by DeSchepper and Treisman (1996) has cast doubt on the view that negative priming reflects the persistence of inhibitory processing. Participants were required to discriminate whether one of two overlapping shapes was the same as or different from a standard shape. The shapes used by DeSchepper and Treisman were not depictions of everyday objects, but instead were meaningless shapes presumed not to have preexisting representations in memory. Nevertheless, participants made same-different discriminations more slowly when the target of comparison on one trial was the same as the distractor on a previous trial. This effect corresponds well with negative priming findings in many other tasks. Astonishingly, they reported that negative priming effects of this sort can survive a lag between the prime and probe display of as long as 30 days.

These data suggest that memorial processing plays an important role in determining negative priming. Indeed, Neill, Valdes, Terry, and Gorfein (1992) have forwarded an episodic retrieval account of negative priming in which the probe stimulus cues the retrieval of previous processing instances involving similar stimuli. They also posited that information related to how the participant responded 
to the prime stimulus is encoded as part of the prime episode. For example, the prime episode may contain an "ignore this stimulus" tag that is linked to the prime distractor. On ignored repetition trials, this response information may be retrieved and conflict with the response to the probe target, thus leading to negative priming. DeSchepper and Treisman (1996) suggested a similar account of negative priming. They argued that episodic representations of abstract shapes are stored together with "action tags" that depict what was done with the stimulus when it was encoded.

However, there are now several documented examples of negative priming that occurs without requiring the participant to "select against" a prime distractor (Milliken \& Joordens, 1996; Ortells \& Tudela, 1996; Park \& Kanwisher, 1994). For example, Milliken and Joordens asked participants to name one of two probe words following presentation of two briefly presented primes. RTs were slower for probe targets that were identical to either of the primes than to unrepeated probe targets. Interestingly, this effect was abolished in a subsequent experiment merely by removing the distracting item from the probe display. In further work, Milliken, Joordens, Merikle, and Seiffert (1998) reported negative priming effects following presentation of a single unattended prime word. In these experiments also, negative priming was observed only when the probe task required selection between target and distractor. Together, these data suggest that processing during the probe merits examination as the potential locus of the negative priming effect.

Note that this theoretical perspective stands in contrast to the view that attentional processing during the prime underlies negative priming. The attribution of negative priming effects to a mechanism that helps one ignore prime items maps priming effects directly to encoding processes. An alternative approach is to assume an indirect relation between encoding processes and priming effects, thus allowing for the possibility that priming effects are determined jointly by encoding and retrieval processes. For example, rather than attribute positive priming for previously attended primes to excitation of an internal representation of the prime target (that persists and is then measured), one might attribute attended repetition effects to the transfer appropriate processing done on the prime target given the requirements of the probe task ( Jacoby, 1983; Morris, Bransford, \& Franks, 1977). ${ }^{1}$ By extension, negative priming for previously ignored primes might not be attributed to the ignoring, and consequent inhibition, of the prime distractor, but rather to the transfer appropriateness, or inappropriateness, of the processing done on the prime distractor given the demands of the probe task. What is required to support this theoretical position is empirical evidence that negative priming can be observed using a procedure that precludes attribution of negative priming to the persisting effect of an ignoring process.
DeSchepper and Treisman (1996) required participants to make same-different discriminations regarding a target shape and a comparison shape. The target shape overlapped a distractor shape that was to be ignored. RTs were faster for targets that were identical to a previously attended target and slower for targets that were identical to a previously ignored distractor than for targets that were unrelated to both the previous target and the distractor (see also Lowe, 1979; Neill, 1997; Tipper, 1985). To examine whether the negative priming effects observed in these studies need be attributed to the process of ignoring a distractor, we examined the more general question of whether the type of processing engaged in during a study task would influence participants' performance in a subsequent same-different discrimination task. A levelsof-processing manipulation (Craik \& Lockhart, 1972) was used to manipulate the memorability of the studied items at the time of the same--different discrimination task. Thus, one group of participants, the corners group, performed a study task in which they recorded the number of angular corners on a study shape (shallow encoding). A second group of participants, the remind group, performed a study task in which they recorded what each study shape reminded them of (deep encoding). The study phase was followed by a same-different discrimination phase and then a recognition memory phase. It was expected that recognition memory for shapes encoded to a deep level would be more accurate than for shapes encoded to a shallow level. Of more direct interest was whether same-different discrimination performance would reveal a pattern of negative priming for target shapes and whether this pattern would depend on the nature of the encoding task.

We first ran this experiment as a pilot demonstration in which 20 undergraduate students in a 3 rd-year cognition research course each tested two of their acquaintances, 1 in each study condition. The procedure was otherwise identical to that described below. As shown in Table 1, participants responded more slowly in the same-different discrimination task when the target shape was studied (967 msec) than when it was novel $(931 \mathrm{msec})$. This effect was attributable primarily to the corners group, although the priming effect was negative in sign for both groups. As shown in Table 2, recognition memory was better for the remind group than the corners group, as expected. These results demonstrate that negative priming of the type reported by DeSchepper and Treisman (1996) can occur without requiring participants to ignore a critical prime.

Experiments $1 \mathrm{~A}$ and $1 \mathrm{~B}$ had two separate purposes. First, we wanted to establish the reliability of the results just described using a more carefully controlled procedure. As such, the experiment was replicated but with a single experimenter and a consistent set of instructions for all participants. The purpose of Experiment $1 \mathrm{~B}$ was to address the possibility that the negative priming effects observed in our pilot experiment may not have had 
Table 1

Mean of Median Latencies (Correct Responses) and Error Rates for the Pilot Experiment and for Experiments $1 A$ and $1 B$

\begin{tabular}{|c|c|c|c|c|c|c|c|c|c|c|c|c|c|}
\hline \multirow[b]{5}{*}{ Experiment } & \multirow[b]{5}{*}{ Repetitions } & \multicolumn{12}{|c|}{ Study Task } \\
\hline & & \multicolumn{6}{|c|}{ Corners } & \multicolumn{6}{|c|}{ Remind } \\
\hline & & \multirow{2}{*}{\multicolumn{2}{|c|}{$\begin{array}{c}\text { Same } \\
\text { RT } \\
\end{array}$}} & \multirow[b]{3}{*}{ ER } & \multicolumn{3}{|c|}{ Different } & \multicolumn{3}{|c|}{ Same } & \multicolumn{3}{|c|}{ Different } \\
\hline & & & & & & & & & $T$ & & RT & & \\
\hline & & $M$ & $S E$ & & $M$ & $S E$ & ER & $M$ & $S E$ & ER & $M$ & $S E$ & ER \\
\hline $\begin{array}{l}\text { Pilot (distractor present) } \\
\begin{array}{l}\text { Difference (Novel - Studied) } \\
\text { (Collapsed over response) } \\
\text { (Collapsed over study task) }\end{array}\end{array}$ & & $\begin{array}{r}917 \\
990 \\
-73\end{array}$ & $\begin{array}{l}58 \\
80\end{array}$ & $\begin{array}{l}0.01 \\
0.02\end{array}$ & $\begin{array}{r}872 \\
896 \\
-24\end{array}$ & $\begin{array}{l}55 \\
43\end{array}$ & $\begin{array}{l}0.02 \\
0.02\end{array}$ & $\begin{array}{r}995 \\
977 \\
18\end{array}$ & $\begin{array}{l}70 \\
63\end{array}$ & $\begin{array}{l}0.02 \\
0.02 \\
24\end{array}$ & $\begin{array}{r}939 \\
1,005 \\
-66\end{array}$ & $\begin{array}{l}61 \\
65\end{array}$ & $\begin{array}{l}0.05 \\
0.03\end{array}$ \\
\hline $\begin{array}{l}\text { 1A (distractor present) } \\
\text { Difference (Novel - Studied) } \\
\text { (Collapsed over response) } \\
\text { (Collapsed over study task) }\end{array}$ & $\begin{array}{l}\text { Novel } \\
\text { Studied }\end{array}$ & $\begin{array}{r}740 \\
752 \\
-12\end{array}$ & $\begin{array}{l}43 \\
41\end{array}$ & $\begin{array}{l}0.02 \\
0.02\end{array}$ & $\begin{array}{c}689 \\
751 \\
-63 \dagger\end{array}$ & $\begin{array}{l}28 \\
36\end{array}$ & $\begin{array}{l}0.04 \\
0.08\end{array}$ & $\begin{array}{r}753 \\
751 \\
2\end{array}$ & $\begin{array}{l}29 \\
30\end{array}$ & $\begin{array}{l}0.03 \\
0.03\end{array}$ & $\begin{array}{r}802 \\
819 \\
-17\end{array}$ & $\begin{array}{l}38 \\
42\end{array}$ & $\begin{array}{l}0.06 \\
0.06\end{array}$ \\
\hline $\begin{array}{l}\text { 1B (distractor absent) } \\
\begin{array}{l}\text { Difference (Novel - Studied) } \\
\text { (Collapsed over response) } \\
\text { (Collapsed over study task) }\end{array}\end{array}$ & $\begin{array}{l}\text { Novel } \\
\text { Studied }\end{array}$ & $\begin{array}{r}668 \\
672 \\
-4\end{array}$ & $\begin{array}{l}53 \\
59\end{array}$ & $\begin{array}{l}0.03 \\
0.03\end{array}$ & $\begin{array}{l}617 \\
620 \\
-3\end{array}$ & $\begin{array}{l}23 \\
26\end{array}$ & $\begin{array}{l}0.04 \\
0.05\end{array}$ & $\begin{array}{r}666 \\
648 \\
18\end{array}$ & $\begin{array}{l}39 \\
41\end{array}$ & $\begin{array}{l}0.03 \\
0.01\end{array}$ & $\begin{array}{r}649 \\
657 \\
-9\end{array}$ & $\begin{array}{l}28 \\
30\end{array}$ & $\begin{array}{l}0.04 \\
0.06\end{array}$ \\
\hline
\end{tabular}

Note-RT, response time in milliseconds; ER, error rate. ${ }^{*} p<.05 . \quad{ }^{\dagger} p<.01$.

the same cause as those effects observed using the more conventional prime selection procedure. This issue is important because our argument is not simply that negative priming can be observed without requiring participants to select between a prime target and a distractor, but also that these negative priming effects may have the same cause as those observed using the more conventional prime selection procedure. If the negative priming effects observed using an unconventional procedure are influenced by the same manipulations as the negative priming effects using a conventional procedure, then a common cause for the two effects seems plausible. To this end, the design of Experiment $1 \mathrm{~B}$ was identical to that of Experiment $1 \mathrm{~A}$ in all aspects but one. In particular, the red distractor in the discrimination phase was no longer visible. Thus participants were required to make a samedifferent discrimination regarding a lone green target and a black standard presented next to each other.

\section{METHOD}

\section{Participants}

Eighty-one undergraduate students of introductory psychology participated for course credit, 40 in Experiment $1 \mathrm{~A}$ and 41 in Experiment $1 \mathrm{~B}$.

\section{Materials}

Stimuli consisted of 157 novel geometric shapes, similar to those employed by DeSchepper and Treisman (1996). The shapes appeared on the monitor of a Macintosh LC475 computer in one of three colorsred, green, or black. Each shape covered an area on the monitor that was approximately $7 \mathrm{~cm}$ horizontally $\times 7 \mathrm{~cm}$ vertically. Participants were provided with a response sheet labeled with the numbers $1-30$ on which they wrote during the study phase.

\section{Design and Procedure}

The experiment consisted of three phases. In the study phase, participants studied a set of abstract shapes. In the same-different discrimination phase, participants completed a series of experimental trials in which they were required to decide whether a green target shape was the same as or different from a simultaneously presented standard shape. The green target shape was superimposed over a red distractor shape and was one of the shapes that appeared in the study phase on half the trials. Finally, in the recognition phase, all the green target shapes from the same-different discrimination task were presented one at a time, and participants were required to judge whether the shapes were "old" (presented in the study phase) or "new" (not presented in the study phase).

The assignment of shapes to the various roles in an experimental trial was achieved in the following manner. Each shape could occur in one of five roles: as a studied green item, as a novel green item, as a red distractor for a studied item, as a red distractor for a novel item, or as a black standard shape. The 150 shapes were randomly divided into five sets of 30 shapes and were rotated across participants so that each set appeared once in each of the five roles just specified. The study task consisted of the 30 green shapes that were designated as studied shapes in the discrimination task. The recognition task consisted of 60 green shapes all of which had been presented as green shapes in the discrimination task but only 30 of which were shapes that participants had seen in the study phase. Five counterbalancing orders were required to rotate the shapes through all possible roles.

Study phase. Participants in the corners group were told that they would be presented with a series of geometric shapes and that their task would be to count the number of angular corners on each shape. Participants were instructed to write this number on the response sheet after the offset of the shape from the monitor. The shapes were presented one at a time in the center of the computer monitor and stayed on the screen for $5 \mathrm{sec}$. Participants were instructed to press the space bar when they were ready for the next shape. The procedure was identical for participants in the remind group, with the exception that they were instructed to write down what each shape reminded them of rather than counting the corners. After the study phase, there was a 5-min delay before the start of the same-different discrimination phase.

Same-different discrimination phase. Each trial in the samedifferent discrimination phase began with a fixation cross $(+)$ that ap- 
Table 2

Proportion of Old Responses for the

Recognition Phase of the Pilot Experiment and for Experiments 1A and 1B

\begin{tabular}{|c|c|c|c|c|c|}
\hline \multirow[b]{3}{*}{ Experiment } & & \multicolumn{4}{|c|}{ Study Task } \\
\hline & & \multicolumn{2}{|c|}{ Corners } & \multicolumn{2}{|c|}{ Remind } \\
\hline & & $M$ & $S E$ & $M$ & $S E$ \\
\hline Pilot (distractor present) & Studied & .38 & .03 & .62 & .03 \\
\hline Difference (Studied - Novel) & Novel & $\begin{array}{l}.16 \\
.22\end{array}$ & .02 & $\begin{array}{l}.10 \\
.52\end{array}$ & .02 \\
\hline \multirow[t]{2}{*}{ 1A (distractor present) } & Studied & .42 & .02 & .59 & .02 \\
\hline & Novel & .23 & .01 & .10 & .01 \\
\hline Difference (Studied - Novel) & & .19 & & .49 & \\
\hline \multirow{2}{*}{ 1B (distractor absent) } & Studied & .41 & .02 & .60 & .02 \\
\hline & Novel & .24 & .02 & .11 & .02 \\
\hline Difference (Studied - Novel) & & .17 & & .49 & \\
\hline
\end{tabular}

peared in the center of the screen for $300 \mathrm{msec}$. The fixation cross was then replaced immediately by a display consisting of three shapes. A green target shape was superimposed on a red distractor shape just to the left of fixation, and a black standard shape was displayed just to the right of fixation. From a viewing distance of approximately $55 \mathrm{~cm}$, the shapes were displayed so that $6.5^{\circ}$ of visual angle separated the center of the standard and target shapes. In Experiment $1 \mathrm{~A}$, the onsets of the three shapes were offset in time from one another by approximately $17 \mathrm{msec}$, with the red distractor appearing first, followed by the black standard, followed by the green target. Experiment 1B was identical with the exception that the red distractor did not appear. The display stayed on the screen until participants responded, and RT was recorded as the latency between onset of the green target shape and the response of the participant. Following the response, the monitor was cleared and $1 \mathrm{sec}$ later the fixation cross signaled the beginning of the next trial.

Before the instructions for this phase were read to participants, a sample display consisting of a target, a distractor, and a standard shape was displayed on the monitor. Participants were told that each trial would start with the appearance of a plus sign in the center of the screen to which they were to attend. After a short time, the plus sign would disappear and be replaced by the three shapes. Participants were told that their task was to decide as quickly and accurately as possible whether the green shape on the left was the same as or different from the black shape on the right. Participants were also told that the green shape would always be superimposed on the red shape and that the green shape and the black shape would always be clearly the same or different. That is, on same trials, the shapes would never be the same but displayed in different orientations. The discrimination task always began with three practice trials consisting of the display that was shown while the instructions were read and two other trials, one requiring a different response and the other requiring a same response. The same set of seven shapes was used for the practice trials for each participant, and the data from these practice trials were not analyzed. Responses were made by pressing one of two keys on the keyboard-“." for same responses, and "c" for different responses.

Recognition phase. The recognition phase occurred immediately after the same-different discrimination phase. All of the shapes that appeared as targets in the discrimination phase were presented to participants in random order, one at a time. The participant's task was to decide as quickly and accurately as possible whether or not each shape was one that they had studied in the first phase of the experiment. Each shape stayed on the screen until participants responded by pressing either the "." key (for old items) or the "c" key (for new items). This test shape then disappeared and was replaced $1 \mathrm{sec}$ later by the following test shape.

\section{RESULTS}

\section{Same-Different Discrimination}

One participant was replaced in Experiment $1 \mathrm{~B}$ because of technical difficulties, and the data from six trials across 4 other participants were dropped from analyses of the same-different discrimination task, also because of technical problems. In each experiment, the median RTs on correctly answered trials in the same-different discrimination phase were computed for each condition, defined by the factorial combination of the repetition (studied vs. novel), response (same vs. different), and study task (corners vs. remind) variables. These medians, and corresponding error rates, were submitted to separate mixed analyses of variance (ANOVAs) that treated repetition and response as within-subjects variables and study task as a between-subjects variable. Means of median RTs and error rates, for both experiments, are displayed in Table 1.

Experiment 1A. In the analysis of the RTs, there was a significant main effect of repetition $[F(1,38)=6.01$, $\left.M S_{\mathrm{e}}=3,323.39, p<.02\right]$. RTs were longer for studied targets $(768 \mathrm{msec})$ than for novel targets $(746 \mathrm{msec})$. There was also a reliable interaction between response and study task $\left[F(1,38)=6.55, M S_{\mathrm{e}}=11,060.70, p<\right.$ $.02]$. To explore this interaction, separate ANOVAs were conducted on the RTs for each study task. For the corners group, studied shapes were responded to more slowly than novel shapes $\left[F(1,19)=8.97, M S_{\mathrm{e}}=3,103.35, p<\right.$ $.01]$. This difference was particularly pronounced for different responses, as revealed by the significant interaction between response and repetition $\left[F(1,19)=5.86, M S_{\mathrm{e}}=\right.$ $2,246.58, p<.03]$. For the remind group, the only significant effect was the main effect of response $[F(1,19)=$ 5.61, $\left.M S_{\mathrm{e}}=12,307.46, p<.03\right]$. Same responses were faster than different responses (752 vs. $811 \mathrm{msec}$, respectively). This effect contrasted in direction with that for the corners group and thus explains the significant response $\times$ study task interaction in the overall analysis.

In the overall analysis of error rates, the only significant effect was the main effect of response $[F(1,38)=$ 19.54, $\left.M S_{\mathrm{e}}=.002, p<.001\right]$. Participants made more errors when a different response was required $(M=.06)$ than when a same response was required $(M=.03)$.

Experiment 1B. There were no reliable effects in the analysis of RTs. In the analysis of error rates, there was a reliable main effect of response $\left[F(1,38)=8.51, M S_{\mathrm{e}}=\right.$ 
$.002, p<.006]$. A higher proportion of errors occurred on trials that required a different response (.06) than on trials that required a same response (.03).

\section{Recognition}

In each experiment, an ANOVA was also conducted on the proportion of old responses in the recognition phase. This analysis treated repetition (studied vs. novel) as a within-subjects variable, and study task (corners vs. remind) as a between-subjects variable. A summary of the proportion of old responses is displayed in Table 2 .

In both Experiments 1A and 1B, the proportion of old responses was higher for studied items than for novel items $\left[F(1,38)=476.02, M S_{\mathrm{e}}=.005, p<.001\right.$ and $F(1,38)=366.49, M S_{\mathrm{e}}=.006, p<.001$, respectively]. More importantly, there was also a reliable interaction between repetition and study task in both experiments $\left[F(1,38)=95.08, M S_{\mathrm{e}}=.005, p<.001\right.$ and $F(1,38)=$ $90.24, M S_{\mathrm{e}}=.006, p<.001$, respectively]. The difference between hits and false alarms was larger for the remind group than for the corners group in both experiments.

\section{DISCUSSION}

The goal of the studies reported in this article was to examine whether negative priming need be attributed to the act of ignoring a prime distractor. In the present experiments, participants studied a set of shapes to either a shallow (corners group) or a deep (remind group) level and then performed a same--different discrimination task using either the studied shapes or novel shapes as targets. In both the pilot experiment and in Experiment 1A, RTs were slower on trials with studied shapes as targets than on trials with novel shapes as targets. This negative priming effect was predominantly attributable to the performance of the corners group. The results from Experiment 1B demonstrated that this negative priming effect is influenced by a manipulation that also influences the negative priming effect found with more conventional procedures. In particular, the negative priming observed in Experiment $1 \mathrm{~A}$ was not observed when the distractor was removed from the probe task, a finding analogous to that reported by numerous other researchers (Lowe, 1979 Milliken \& Joordens, 1996; Moore, 1994; Tipper \& Cranston, 1985). A the same time, recognition performance was nearly identical in all three experiments, with shapes studied to a deep level recognized more accurately than shapes studied to a shallow level. Clearly, the different results in Experiments $1 \mathrm{~A}$ and $1 \mathrm{~B}$ cannot reasonably be attributed to differences in the encoding of the shapes. Instead, the critical difference between the two studies that produced the different patterns of RTs must be related to the nature of processing in the same-different discrimination task itself.

One additional finding should be noted. The negative priming effects observed in the pilot experiment and in Experiment $1 \mathrm{~A}$ were similar to each other when collapsed across response and across study task. Further, the signs of the four priming effects defined by the factorial combination of the study task and response variables were consistent across experiments. However, for the corners study task, the negative priming effect appears to have been driven by performance on same trials in the pilot experiment, but by performance on different trials in Experiment $1 \mathrm{~A}$. We are currently not aware of the reason for this difference, if indeed there is a reason other than measurement error. Future work will address this issue.

\section{Accounting for the Present Data}

In the introduction, a general framework was outlined that motivated the present studies. In particular, it seems possible that the prime selection task, conventionally used to measure negative priming, may be one of many encoding manipulations that modulate priming effects. By this view, the positive priming that often results in attended repetition conditions might be attributed to transfer appropriate processing, given that the probe task requires the subject to attend and respond to an identical item. In contrast, the negative priming observed in ignored repetition conditions might be attributed to transfer inappropriate processing. To extend this general framework to the data presented here requires an explanation for why negative priming occurred primarily in the corners condition but not in the remind condition of Experiment $1 \mathrm{~A}$, whereas recognition performance was better in the remind condition than it was in the corners condition.

We speculate that for a priming effect to be observed, some form of integration between the representations of the probe target and the related prime must occur. Further, this integration may be sensitive to the similarity of processing requirements of the prime and probe tasks (see Neill, 1997). This assumption may explain why priming effects were observed in the corners condition but not in the remind condition; the match between the processing requirements of the corners task and the same-different discrimination task may have been greater than that for the remind task. For the transfer to be negative rather than positive, we must assume that the process of integration interferes with, rather than facilitates, the discrimination required in the probe task. One explanation for this interference makes reference to source discrimination (Johnson, Hashtroudi, \& Lindsay, 1993). By this view, an implicit match between a perceptual target and a memorial representation may be confused with the explicit task of matching a target and standard. ${ }^{2}$ In effect, the source of evidence favoring a same-different decision may require monitoring to ensure that responses are based on evidence from the comparison of a target and standard rather than a comparison between a target and a memorial representation. The elimination of the distractor from the same-different discrimination task may result in less source confusion, either by virtue of the task being less difficult or because a decision can be made before the retrieval of the prime occurs. Further, the implicit integration process that is sensitive to the contextual match between study and test may well be different from the informational basis on which recognition judgments are made (Jacoby, 1983). Such a difference would explain why recognition performance was better in the remind task but priming effects were larger in the corners task.

\section{On the Relation Between These and Other Negative Priming Data}

Many researchers have argued that negative priming provides a measure of inhibition used to aid selection of prime targets and to ignore distractors (Neill, 1977; Tipper, 1985). Others have suggested that negative priming is determined by the retrieval of conflicting response information that is encoded as part of the prime episode (Neill et al., 1992). In other words, an "ignore this stimulus" tag may be associated with the prime distractor, which when retrieved on ignored repetition trials interferes with the task of responding to that previously ignored stimulus. We suggest that the results reported in the present article are problematic for these conventional accounts of negative priming because the negative priming effects observed here cannot reasonably be attributed to a process of ignoring. Participants did not ignore the shapes when they were presented; they studied them. Thus, although we must agree with other researchers who have suggested that retrieval processes play an important role in negative priming (DeSchepper \& Treisman, 1996; Neill et al., 1992), we suggest that these retrieval processes may be more profitably studied by abandoning the view that ignoring in any direct way causes negative priming.

Of course, this conclusion is based on an assumption that the negative priming effects observed here and those observed using the conventional prime selection task have the same cause. In the experiments reported here, and in other recent studies that point to the same conclusion (Milliken \& Joordens, 1996; Milliken et al., 1998), this issue has been addressed by demonstrating the sensitivity of negative priming, measured without a prime selection task, to the selection requirements of the probe task. To the extent that negative priming measured without a prime selection task shares empirical properties with negative priming measured with a prime selection task, it seems reasonable to conclude that the two may share a common cause. Although we acknowledge that the explanation forwarded here is not required by the present data, 
the possibility that negative priming is not caused directly by a process of ignoring but by the interaction between the processing required at encoding and at retrieval seems to be an issue worth pursuing.

\section{REFERENCES}

CRAIK, F. I. M., \& LockHART, E. (1972). Levels of processing: A framework for memory research. Journal of Verbal Learning \& Verbal Behavior, 11, 671-684.

DeSchePPER, B., \& TREisman, A. (1996). Visual memory for novel shapes: Implicit coding without attention. Journal of Experimental Psychology: Learning, Memory, \& Cognition, 22, 27-47.

$J_{A C O B Y}$ L. L. (1983). Remembering the data: Analyzing interactive processes in reading. Journal of Verbal Learning \& Verbal Behavior, 22, 485-508.

Johnson, M. K., Hashtroudi, S., \& Lindsay, D. S. (1993). Source monitoring. Psychological Bulletin, 114, 3-28.

LowE, D. G. (1979). Strategies, context, and the mechanism of response inhibition. Memory \& Cognition, 7, 382-389.

MARCEL, A. J. (1980). Conscious and preconscious recognition of polysemous words: Locating the selective effects of prior verbal context. In R. S. Nickerson (Ed.), Attention and performance VIII (pp. 435 457). Hillsdale, NJ: Erlbaum.

Milliken, B., \& JoORdens, S. (1996). Negative priming without overt prime selection. Canadian Journal of Experimental Psychology, $\mathbf{5 0}$ 333-366.

Milliken, B., Joordens, S., Merikle, P. M., \& Seiffert, A. E. (1998). A re-evaluation of the implications of negative priming. Psychological Review, 105, 203-229.

MoORE, C. M. (1994). Negative priming depends on probe-trial conflict: Where has all the inhibition gone? Perception \& Psychophysics, 56, 133-147.

Moran, J., \& Desimone, R. (1985, August). Selective attention gates visual processing in the extrastriate cortex. Science, 229, 782-784.

MorRis, C. D., Bransford, J. D., \& FranKs, J. J. (1977). Levels of processing versus test-appropriate strategies. Journal of Verbal Learning \& Verbal Behavior, 16, 519-533.
NeILL, W. T. (1977). Inhibition and facilitation processes in selective attention. Journal of Experimental Psychology: Human Perception \& Performance, 3, 444-450.

NeILL, W. T. (1997). Episodic retrieval in negative priming and repetition priming. Journal of Experimental Psychology: Learning, Memory, \& Cognition, 23, 1291-1305.

Neill, W. T., Valdes, L. A., Terry, K. M., \& Gorfein, D. S. (1992). The persistence of negative priming: II. Evidence for episodic trace retrieval. Journal of Experimental Psychology: Learning, Memory, \& Cognition, 18, 993-1000.

Ortells, J. J., \& Tudela, P. (1996). Positive and negative semantic priming of attended and unattended parafoveal words in a lexical decision task. Acta Psychologica, 94, 209-226.

PARK, J., \& KANWISHER, N. (1994). Negative priming for spatial location: Identity mismatching, not distractor inhibition. Journal of Experimental Psychology: Human Perception \& Performance, 20, 613-623.

Posner, M. I., \& CoHEN, Y. (1984). Components of visual orienting. In H. Houma \& D. G. Bouwhuis (Eds.), Attention and performance X: Control of language processes (pp. 531-556). Hillsdale, NJ: Erlbaum.

TiPPER, S. P. (1985). The negative priming effect: Inhibitory effects of ignored primes. Quarterly Journal of Experimental Psychology, 37A, 571-590.

TIPPER, S. P., \& CRANSTON, M. (1985). Selective attention and priming: Inhibitory and facilitatory effects of ignored primes. Quarterly Journal of Experimental Psychology, 37A, 591-611.

\section{NOTES}

1. The idea that transfer appropriate processing plays a role in negative priming has benefited from discussions with Lisa Williams and Bruce Whittlesea, and more recently with Tram Neill.

2. We thank an anonymous reviewer for comments on this issue.

(Manuscript received April 29, 1997; revision accepted for publication November 17, 1997.) 